\title{
Designing and Implementing a Database for Thesis Data Management by Using the Python Flask Framework
}

\author{
Suraya, Muhammad Sholeh* \\ Department of Informatics, Faculty of Industrial Technology, Institut Sains \& Teknologi AKPRIND Yogyakarta, Yogyakarta, \\ Indonesia \\ *Corresponding author E-mail: muhash@akprind.ac.id
}

\begin{abstract}
Manuscript received 29 Oct 2021; revised 10 Dec 2021; accepted 15 Jan 2022. Date of publication 20 Jan 2022

This study aims to implement the database design used in thesis data processing using Flask. The results of the database design produce four tables, namely the lecturer table is used to store lecturer data, the student table is used to store student data, the title of thesis table is used to store data related to student thesis and the guidance table contains history during guidance with the supervisor, The design of the thesis data processing database was developed using Flask. Flask is a web framework written in Python. Flask serves as the application framework and the interface of the web-based flask application. In this research, the methodology used is to implement database development which consists of system analysis, logical design, physical design and implementation. The database design methodology is carried out by 1 . Building a local conceptual data design based on user views, 2. Building and validating local logical data models, 3. Building and validating logical data models, 4. Translating logical data models for the database management system, 5. Designing and implementation of physical representation. The results show that the process of creating a thesis data management database can be done using the Flask framework. The development process using the flask framework includes the process of creating databases, tables and reading, adding, repairing and deleting data. In making the application, the application is divided into 2, namely the application used for database management and the application used to display website-based results that are used to display the results of data processing from the application. Implementation of data structures in the database design and applications used include programming language: Python 3.7.0, framework for displaying web-based data: Flask 1.1.2, and database management system using SQLite.
\end{abstract}

Keywords: Database, Thesis, SQLite, Flask.

\section{Introduction}

Information system-based data management is currently a basic need, including in thesis data management. With the application, of course, it makes it easier to manage information and the data search process. The current information management system is mostly website-based. The use of this website is of course with the consideration that the system built can be used by users who have access rights and can be done anywhere, anytime. The importance of information for the public or for authorized users is increasingly being used and developed by the industry. The use of website-based information systems is increasingly being used in the industrial world. People are also increasingly familiar with the use of information systems. Currently, people are familiar with the use of trade information systems (e-commerce), banking information systems (e-banking) and the use of other information systems [1].

Information system support in administrative management is very necessary in data management. The existence of an information system is expected to facilitate the process of storing data and the process of searching for data. In addition, the developed information system can reduce the risk of user errors in using data. The data that will be entered in the information system will of course be validated from errors so that the data stored in a database has been avoided from wrong data. By using the management information system or users who have access, they can use it in decision making and to carry out operations within a company. An information system is a collection of various components that work together to work on a process to achieve certain goals. The process carried out by the information system is a process used to record transactions, maintain data stored in databases, and present reports and information on something that has been determined [2] [3].

Application development must pay attention to the characteristics of valid and reliable information systems. The process of developing web-based information systems is currently growing rapidly. This is the use of a website that provides convenience and is open source in the development process (coding). Programming languages can use HTM, ASP, PHP and can be combined with CSS and Java Script. [4] 
[5] [6]. The system development process can use various options including using the Python Flash Framework. Flask is a web framework used in python programming. [2], [3]. The Flask web framework was developed using the Python programming language, so before using Flask, in application development, you must install Python on the device to be used.

In addition to programming languages, the process of developing information systems requires reliable database support. There are many alternatives to choose from in the use of database management systems. Database management system is an application that can be used in database management. With this application the processed data can be managed data that has been stored. By using a DBMS, data creation, maintenance, control, and access to data sources can be carried out in a practical and efficient way. DBMS can be used to accommodate various types of users and can be adjusted according to different user access rights. Along with the development of databases, alternatives in the use of database models are becoming diverse, namely by using SQL (Structured Query Language) or noSQL. The database model that is widely used in the development of information systems is the SQL database model or the relational database model. The process of storing data in the relational model consists of several tables and the relationship between tables is done by doing the relation process. [7], [8], [9], [10].

The development of the information system used in the management of thesis data uses the Flask framework which is based on Python programming and uses the Sqlite DBMS. Before implementing the development of information systems, database design is carried out. The results of the database design produce 4 main tables that are used to store data used to store student data, lecturer data and thesis processing transaction data.

\section{Literature Review}

The implementation of this thesis data management used SQLite. SQLite is a relational database management system (DBMS) built by using the $\mathrm{C}$ programming language. SQLite is not included in the client-server database engine like MYSQL that has to use web server to running it. The SQLite result is a single file. SQLite is a DBMS that does not require a special installation process so that using SQLite is quite simple and practical [11] [12] [13].

Several studies on the use of SQLite were conducted by Setiyadi [14], Yuvaraj [15], and Bagus [16]. The study of Setiyadi developed an application that was used as exam and presentation timer. The application stored the data used in the exam and presentation timer. All data was stored in a SQLite DBMS [14]. The study of Yuvaraj developed an inventory application by using SQLite as a database [15]. The study of Bagus investigated the use of SQLite to design a database for android applications. Database implementation for android applications is one of the problems that cause difficulties in developing android applications. One of the databases that can be used in android applications that require a database is SQLite [16]. Other studies that used SQLite as a DBMS were conducted by [17],[18],[19] There are many programming languages in application development, especially web-based applications, one of which is Python. A feature in Python that supports web programming is the flash library. Flask framework is a framework that can be used in Python and is used in creating web-based applications. Flask is a micro framework for web applications [20]. Several studies on the use of Python language and the use of Flask framework were carried out by Susanti [21] and Ramdani [22]. The study of Susanti developed a web-based master planogram application using the Flask framework with the Python programming language. A planogram is a method that can be used in the planning, structuring, and placement of products according to certain categories. Ramdani [22] used the Flask Web Framework to make an application in determining "Uang Kuliah Tunggal" (UKT). UKT is a tuition fee whose amount is determined by considering the financial condition of the students. Other studies on the use of Python language and the use of Flask framework are Putra [23], Adawadkar [24], Wang [25], and Halachev [26].

Based on the problem, the researchers conducted this study on the design and implementation of a database for thesis data management by using the Python Flask framework [27].

\subsection{SQLite}

Many DBMS (Database Management System) that can be used in database implementation, one of the popular DBMS used is SQLite. SQLite is a SQL database engine that is directly embedded or in the application. In the use of SQLite, the user does not need a server. SQLite reads and writes directly to predefined disk files. SQLite databases have features such as Mysql databases that are equipped with the ability to create multiple tables, indexes, triggers, and views. The database file format is cross-platform. So that it can perform the process of copying between databases or between different architecture platforms. SQLite advantages include SQLite does not require a separate process or server system, zero-configuration, data is stored in a single file stored on disk and is cross-platform, SQLite is very small and light and independent [28]. An example script to create a database is:

D:1>sqlite3

SQLite version 3.36.0 2021-06-18 18:36:39

Enter ".help" for usage hints.

Connected to a transient in-memory database.

Use ".open FILENAME" to reopen on a persistent database.

sqlite> create table members(

...> integer id,

...> name varchar(20),

...> address varchar(32)

...>);>

\subsection{Python}

There are more and more alternatives that can be used in the programming language used in application development. Python is one of the languages that can be used in desktop and website-based programming. Python is very easy to use, especially in basic programming. This is because the python language commands are simple, neat and concise. Python is one of the most powerful languages in the use and application of scientists, especially big data, data mining, deep learning, data science to machine learning. When compared to other programming languages, commands in Python tend to be easy to learn, easy to read, and have shorter commands. Python can also be used on various operating systems such as Windows, Linux and Mac OS [24]. 


\subsection{Framework Flask}

Flask Framework is a python framework that can be used to create web-based applications. Flask allows developers to build a Pythonbased web application and allows developers to use various types of extensions as needed. Flask provides a number of standard functions for developers to add multiple libraries or plugins to an extension. The advantages of flask include 1. easy to understand, Flask is a framework that is suitable for beginners because it is easy to understand. This framework is also simple enough that developers can create navigation and applications easily, 2. Flexible, Flask is a simple and minimalist framework, so that almost all parts of Flask are modified [29],[20]. The flask manufacturing process includes:

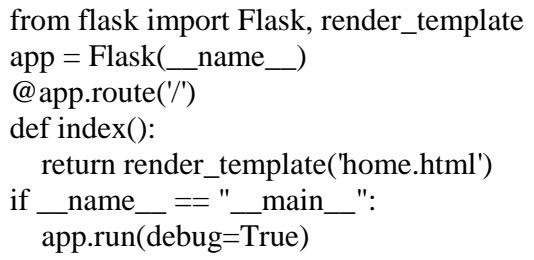

\section{Methods}

The researchers carried out the stages in the database development life cycle that were requirement analysis, logical design, physical design, and implementation [9]. Database implementation was done by building data structures on tables. Database design was done based on the data and information required. The process of database design was carried out by meeting all the needs of data and user information and designing data structures in order to minimize problems in database design such as data duplication, data consistency, and operational speed. To achieve a good result of database design, the database design process was carried out with normalization [30],[31],[32]. The database design was carried out in several stages that were building the design of local conceptual data based on user views, building and validating local logical data models, building and validating the model of global logical data, translating the model of global logical data for DBMS, designing and implementing physical representations.

The applications used to implement data structures in database design was the programming language of Python 3.7.0. The framework used to display web-based data display was Flask 1.1.2, and for DBMS, the researchers used SQLite.

\section{Results and Discussion}

The implementation of the Flask framework was done to the database design for the thesis data management. The thesis data is very important, especially to know the title, the thesis supervisor, and the decree of thesis supervisor. The most important data was the thesis title, the date of the decree of thesis supervisor, the thesis supervisor (both the main supervisor and the co-supervisor), and the thesis consultation form. There were 4 tables that were the lecturer table which stored the lecturer data, the student table which stored the student data, the tittle of thesis table which stored the data of the students' theses, and the guidance card table which stored the data of thesis consultation. The four tables and the relationships between the tables are presented in the figure 1 .

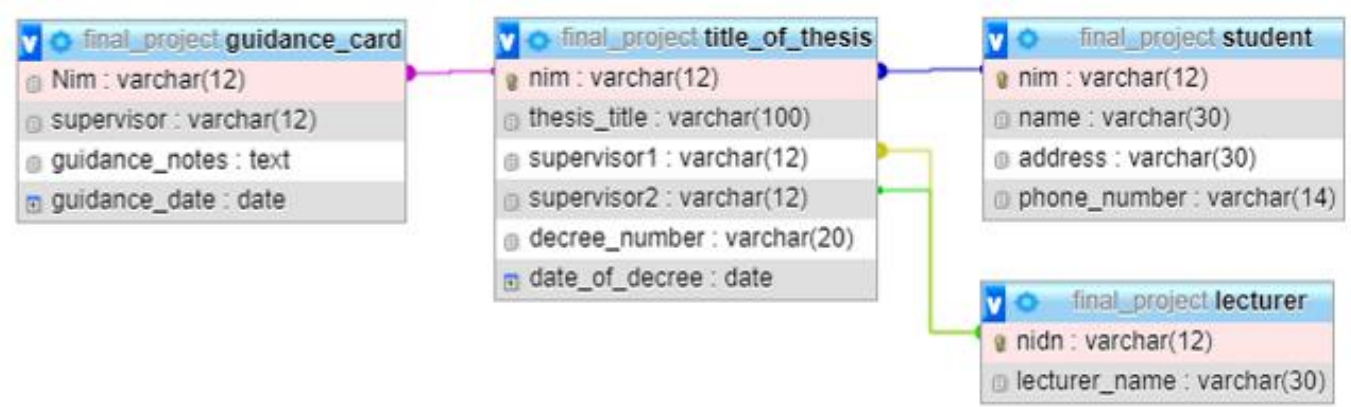

Fig. 1: The relationships between tables

The initial process in using Flask was installing the Flask library. The command to install the Flask library was c: > pip install flask. The process of checking whether Flask had been installed was by typing the import Flask command in the Python interpreter or by looking at the list of the library that had been installed. The figure 2 shows the display of checking the Flask library by typing the import Flask command that was 〉 import flask. In figure 2, there is no error message. It means that the Flask library has been installed. The figure 3 shows the display of checking the Flask library by looking at the list of the library that had been installed. The command was pip list. This command was typed in the command line. In Figure 3, the installed library was displayed. From the list, there is a flash library, which means that the library has been installed.

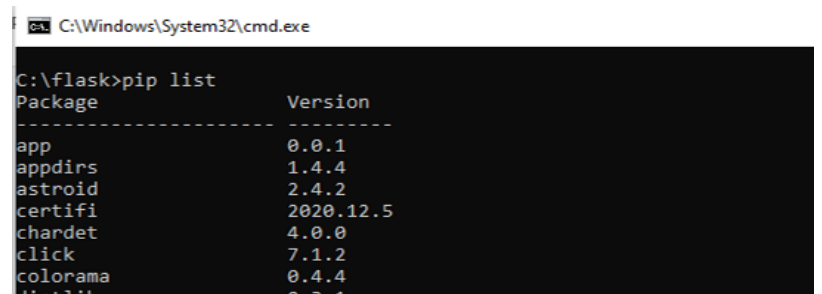

Fig. 2: The command to check the Flask library (with the command of $\gg>$ import flask) 


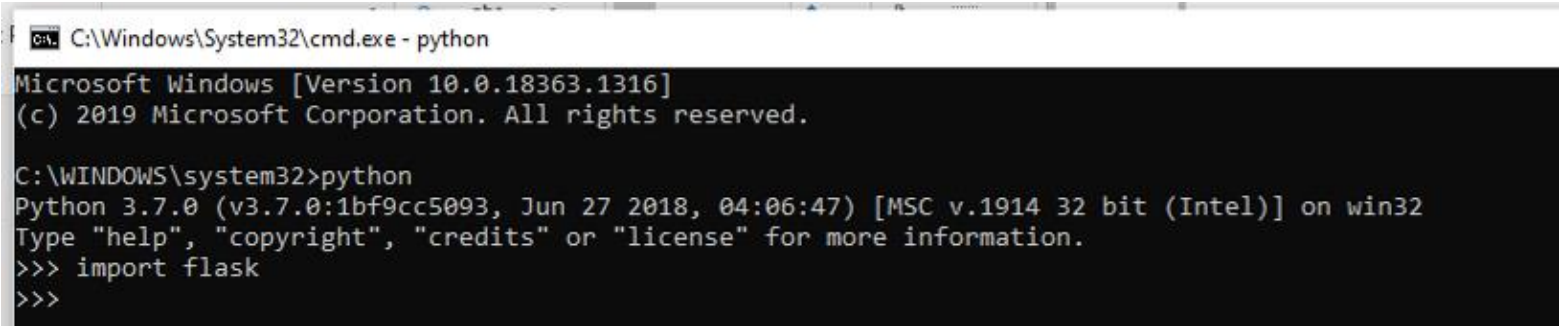

Fig. 3: The command to check the Flask library (with the command of $\mathrm{c}>$ pip list)

The database design was implemented in DBMS SQLite by using Python, and the process of this database creation had not used the flask library. The process of creating the database and examples of creating the student table are in the table 1 .

Table 1. Source code to make the database "Final Project" and table "Student"

\begin{tabular}{|c|c|}
\hline >>> import sqlite3 & Using / installing the SQLite library \\
\hline 〉> conn=sqlite3.connect('final_project') & $\begin{array}{l}\text { The command of connect () was used to determine the name of the } \\
\text { database to be accessed. If the database name was not in the active } \\
\text { directory, Python would create a database named "final project". }\end{array}$ \\
\hline$\gg>\mathrm{db}=$ conn. cursor() & $\begin{array}{l}\text { Creating object database from the cursor class to execute SQL com- } \\
\text { mands }\end{array}$ \\
\hline 〉> db.execute("' & \multirow{8}{*}{$\begin{array}{l}\text { The object database ran the execute command. The execute com- } \\
\text { mand was an SQL command to create the student table with the data } \\
\text { structure that consisted of the NIM (student registration number), } \\
\text { name, address and phone_number }\end{array}$} \\
\hline ... CREATE TABLE student ( & \\
\hline ... NIM CHAR(10) NOT NULL PRIMARY KEY, & \\
\hline ... name CHAR(40) & \\
\hline ... address CHAR(40), & \\
\hline ... phone_number CHAR(15) & \\
\hline ...) & \\
\hline ..."') & \\
\hline <sqlite3.Cursor object at 0x01D785E0> & Indicating that the process was executed successfully \\
\hline >> conn.close () & Closing the connection \\
\hline
\end{tabular}

The database management consisted of displaying data, deleting data, changing data, and adding data. There were two applications that were the application developed with Flask that is used for the database management and the application used to display website-based results that were used to display the results of data processing from the application made with Flask. In Table 2, a snippet of the Python program using the Flask library is presented in database management. The management application made with Flask is used for data manipulation processes such as reading, adding data, etc.

Table 2. An example of a Python program using the Flask library

\begin{tabular}{|c|c|c|}
\hline 1. & from flask import Flask, render_template, request, redirect, url_for & \multirow[t]{2}{*}{ Installing / using the Flask library } \\
\hline 2. & application = Flask (_name__ $)$ & \\
\hline 3. & @ application.route('/') & Calling index.html file \\
\hline 4. & def index () : & Declaring the creation of the index function \\
\hline 5. & import sqlite3, os & Using the SQLite library \\
\hline 6. & databaseName $=$ os.getcwd ()$+$ '/data/final_project.db' & \multirow[t]{4}{*}{ Connection tothe database of final_project.db } \\
\hline 7. & conn $=$ sqlite3. connect $($ databaseName $)$ & \\
\hline 8. & cursor $=$ conn. cursor () & \\
\hline 9. & container $=[]$ & \\
\hline 10. & $\begin{array}{l}\text { for NIM,nama, tittle,lecturer_name in cursor.execute('SELECT s.NIM, } \\
\text { s.name,t.tittle,l.lecturer_name FROM lecturer as } 1 \text {, title_of_thesis as t } \\
\text { student as s where t.NIM=s.NIM and t.supervisor1=1.NIDN'): }\end{array}$ & \multirow[t]{2}{*}{$\begin{array}{l}\text { Query command to display thesis data consisting } \\
\text { of name, thesis title, and main supervisor }\end{array}$} \\
\hline 11. & container.append((NIM,nama,tittle,lecturer_name)) & \\
\hline 12. & cursor.close() & \multirow[t]{2}{*}{ Database closure } \\
\hline 13. & conn.close () & \\
\hline 14. & return render_template('index.html', container=container) & \\
\hline
\end{tabular}

The program presented in table 2 is a Python program that was used to display thesis data. The query process to display the thesis data is in the row 10. The row 10 is the command used to query the student, lecturer, and title_of_thesis tables. The results of the program were displayed in a browser with the url http: // localhost: 5000. The process of sending to the view index () to the index.html template used the command the row 11. In the row 11, there is a container command which is an object used to hold all rows of data retrieved from the database. The simple index.html program is in the table 3. 
Table 3. Program index.html

\begin{tabular}{|c|c|c|}
\hline 1. & $\langle\mathrm{html}\rangle$ & \\
\hline 2. & 〈head> & \\
\hline 3. & $<$ title $>$ thesis data $</$ title $>$ & \\
\hline 4. & $\langle/$ head $>\langle$ body $>$ & \\
\hline 5. & $<$ h2 $>$ Data Skripsi $</$ h2 $>$ & \\
\hline 6. & 〈table border="1"> & \\
\hline 7. & $\langle\operatorname{tr}\rangle$ & \\
\hline 8. & $<$ th width $=60>$ NIM $</$ th $>$ & \multirow[t]{4}{*}{ Creating table and column headings } \\
\hline 9. & $\langle$ th width $=150>$ Student Name $</$ th $>$ & \\
\hline 10. & $\langle$ th width $=250>$ thesis title $</$ th $>$ & \\
\hline 11. & $<$ th width=250 $>$ Main supervisor $</$ th $>\quad</$ tr $>$ & \\
\hline 12. & $\{\%$ for data_skripsi in container $\%\}$ & \multirow{8}{*}{$\begin{array}{l}\text { Displaying the contents of the container variable sent from the } \\
\text { python program (utama.py). }\end{array}$} \\
\hline 13. & $\langle\operatorname{tr}\rangle$ & \\
\hline 14. & $\langle\mathrm{td}\rangle\{\{$ data_skripsi[0] $\}\}</ \mathrm{td}\rangle$ & \\
\hline 15. & $\langle\mathrm{td}\rangle\{\{$ data_skripsi $[1]\}\}\langle/ \mathrm{td}\rangle$ & \\
\hline 16. & $\langle\mathrm{td}\rangle\{\{$ data_skripsi[2] $\}\}</ \mathrm{td}\rangle$ & \\
\hline 17. & $\langle\mathrm{td}\rangle\{\{$ data_skripsi[3] $\}\}</ \mathrm{td}\rangle$ & \\
\hline 18. & $\{\%$ endfor $\%\}$ & \\
\hline 19. & $\langle/$ table $></$ body $>\quad</$ html $>$ & \\
\hline
\end{tabular}

In data management, the CRUDs process (create, read, update, delete and search) is a basic command and the main command in information system management. The table 4 is an example of a program used to add data, especially student data stored in student tables.

Table 4. The program used to add data

1.@ @application.route('/add_student', methods=['GET','POST']) If there was a link call of add_student.html, the add_student

\begin{tabular}{|c|c|c|}
\hline 2. & def add_student(): & The start of the add_student function \\
\hline 3. & import sqlite3, os & The use of the SQLite library \\
\hline 4. & databaseName $=$ os.getcwd ()$+$ '/data/final_project.db' & \multirow{4}{*}{ The connection to the database of final_project.db } \\
\hline 5. & conn $=$ sqlite 3. connect $($ databaseName $)$ & \\
\hline 6. & print(databaseName) & \\
\hline 7. & cursor $=$ conn. cursor () & \\
\hline 8. & container $=[]$ & \multirow{5}{*}{ Holding data entered via the form to add data } \\
\hline 9. & if request.method == 'POST': & \\
\hline 10. & nim $=$ request.form['NIM'] & \\
\hline 11. & name $=$ request.form['Name'] & \\
\hline 12. & address $=$ request.form['Address'] & \\
\hline 13. & $\mathrm{hp}=$ request.form['hp'] & \\
\hline 14. & data $=$ nim, name, address, $\mathrm{hp}$ & \\
\hline 15. & $\begin{array}{l}\text { cusor.execute('INSERT INTO student VALUES(?,?,?,?)', } \\
\text { data) }\end{array}$ & The SQL command to add data to the student table \\
\hline 16. & conn.commit() & \\
\hline 17. & conn.close() & \\
\hline 18. & return redirect(url_for('index')) & Database closure \\
\hline 19. & else: & \\
\hline 20. & $\begin{array}{l}\text { return render_template('add_student.html', } \\
\text { container=container) }\end{array}$ & Returning to the add_student.html program \\
\hline
\end{tabular}

The row 10-13 functioned to store data that entered by the users in the add_student.html form and the storage process in the student table was executed the row 15.

\section{Conclusion}

The Flask framework can be a solution for the use of web-based Python programming. There are two applications: the application developed in Python using the Flask framework and the web-based application that is used as user interfaces. The web-based interface process is used to display data / information, database management such as delete, update, edit, searching.

In this study, the data stores in 4 tables that are the student table, the lecturer table, tittle_of_thesis table, and guidance_card table. The design process is carried out by paying close attention to stored data, especially avoiding duplication of data and easy accessing process. The implementation of the database design uses SQLite

\section{References}

[1] Ula M, Tjut Adek R and Bustami B 2021 Emarketplace Performance Analysis Using PIECES Method Int. J. Eng. Sci. Inf. Technol.

[2] Wing Wahyu Winarno 2021 Sistem Informasi dan Teknologi Informasi Sebuah Pengantar (Wingit Press)

[3] S Pasaribu J 2021 Development of a Web Based Inventory Information System Int. J. Eng. Sci. Inf. Technol. 1 
[4] Acai Sudirman, Muttaqin Muttaqin, Ramen A. Purba, Alexander Wirapraja, Leon A. Abdillah, Fajrillah Fajrillah, Fatimah Nur Arifah, Julyanthry Julyanthry, Ronal Watrianthos J S 2020 Sistem Informasi Manajemen (Yayasan Kita Menulis)

[5] Dahmani Z and Belarbi S $2014 \mathrm{New}$ results for fractional evolution equations using Banach fixed point theorem Int. J. Nonlinear Anal. Appl. 5

[6] Firmansyah M F and Maulana H Z 2021 Empirical Study of E-Learning on Financial Literacy and Lifestyle : A Millenial Urban Generations Cased Study Int. J. Eng. Sci. Inf. Technol. 1 75-81

[7] Andreas Meier M K 2019 SQL \& NoSQL Databases: Models, Languages, Consistency Options and Architectures for Big Data Management (Springer)

[8] Jeffrey A. Hoffer, Venkataraman Ramesh H T 2016 Modern Database Management

[9] Toby J. Teorey, Sam S. Lightstone, Tom Nadeau H V J 2011 Database Modeling and Design: Logical Design (Elsevier)

[10] Carlos Coronel S M 2017 Database Systems: Design, Implementation, \& Management (Cengage)

[11] Siahaan V 2020 MAHIR PYTHON/SQLITE: Membuat Dari Nol Database Sekolah (Balige Publishing)

[12] Hendry 2015 Cepat Mahir MySQL dan SQLite (Elex Media Komputindo)

[13] Maisa Putra D and Alfauzain A 2021 Design Of Tracer Using Microsoft Access Unit In Medical Record Primary Health In Padang Int. J. Eng. Sci. Inf. Technol. 1

[14] Setiyadi A and Harihayati T PENERAPAN SQLITE PADA APLIKASI PENGATURAN WAKTU UJIAN DAN PRESENTAS Maj. Ilm. UNIKOM 13 221-6

[15] Yuvaraj K, Oorappan G M, Megavarthini K K, Pravin M C, Adharsh R and Kumaran M A 2020 Design And Development Of An Application For Database Maintenance In Inventory Management System Using Tkinter And Sqlite Platform Design And Development Of An Application For Database Maintenance In Inventory Management System Using Tkinter And Sqlite Pl IOP Conf. Ser. Mater. Sci. Eng. Pap.

[16] Bagus R, Putra D, Budi E S and Kadafi A R 2020 Perbandingan Antara SQLite, Room , dan RBDLiTe dalam Pembuatan Basis Data pada Aplikasi Android JURIKOM (Jurnal Ris. Komputer) 7 376-81

[17] Trentadue R, Valassi A and Kalkhof A 2017 Text Data Storage Method Modification for SQLite Relational Database Text Data Storage Method Modification for SQLite Relational Database J. Phys. Conf. Ser. Pap. 5-10

[18] Kengalagutti D and G A C 2020 Comparing Database Management Systems : MySQL, PostgreSQL, SQLite Int. Res. J. Eng. Technol. 7 2238-41

[19] Bhosale S T and Patil P 2015 SQLite : Light Database System Int. J. Comput. Sci. Mob. Comput. 3 882-5

[20] Raharjo B 2017 Belajar Otodidak Flash (Bandung: Penerbit Informatika)

[21] Susanti E and Mailoa E 2020 RESTful API Implementation in Making a Master Data Planogram Using the Flask Framework ( Case Study: PT Sumber Alfaria Trijaya, Tbk ) J. Inf. Technol. Comput. Sci. 5 255-69

[22] Ramdani A L and Firmansyah H B 2018 Clustering Application for UKT Determination Using Pillar K-Means Clustering Algorithm and Flask Web Framework Indones. J. Artif. Intell. Data Min. 153

[23] Putra M G L and Putera M I A 2019 Analisis Perbandingan Metode Soap Dan Rest Yang Digunakan Pada Framework Flask Untuk Membangun Web Service SCAN - J. Teknol. Inf. dan Komun. 14 1-7

[24] Adawadkar K 2017 Python Programming-Applications and Future Int. J. Adv. Eng. Res. Dev. 4 1-4

[25] Wang J and Wang W 2018 Design of Data Mining of WeChat Public Platform Based on Python Design of Data Mining of WeChat Public Platform Based on Python J. Phys. Conf. Ser. Pap.

[26] Halachev P 2020 Web application with Python and security of the information system INTERNATIONAL 6 103-6

[27] Dharma Utamayasa I G 2021 Efect Physical Activity and Nutrition During The Covid-19 Pandemic Int. J. Eng. Sci. Inf. Technol. 1

[28] Siahaan V and Sianipar R H 2019 LANGKAH DEMI LANGKAH PEMROGRAMAN DATABASE SQLITE DAN MYSQL DENGAN GUI PYTHON (SPARTA PUBLISIHING)

[29] Copperwaite M and Leifer C 2015 Learning Flash Framework (Packt Publishing)

[30] Agus Wahyu Widodo D K 2017 Sistem Basis Data (Malang: Universitas Brawijaya Press)

[31] Pamungkas C A 2017 Pengantar dan Implementasi Basis Data (Yogyakarta: Deepublish Publisher)

[32] Adyanata L 2016 Basis Data Dasar 